\title{
Consenso Brasileiro em Transplante de Células-Tronco Hematopoéticas: Comitê de Hemoglobinopatias
}

\section{Brazilian Consensus Meeting on Stem Cell Transplantation: Hemoglobinopathies Committee}

\author{
Belinda P. Simões ${ }^{I}$ \\ Fabiano Pieroni ${ }^{2}$ \\ George M. N. Barros ${ }^{3}$ \\ Clarisse L. Machado ${ }^{4}$ \\ Rodolfo D. Cançado 5 \\ Marco Aurélio Salvino ${ }^{6}$ \\ Ivan Angulo ${ }^{7}$ \\ Julio Cesar Voltarelli ${ }^{8}$
}

\begin{abstract}
Os distúrbios hereditários das hemoglobinas são as doenças genéticas mais frequentes do homem e mais difundidas no mundo, abrangendo sobretudo continentes como África, Américas, Europa e extensas regiões da Ásia. Estima-se que haja 270 milhões de portadores de hemoglobinopatias no mundo, dos quais 80 milhões são portadores de talassemia. Aproximadamente 60 mil crianças nascem anualmente no mundo com talassemia e 250 mil com anemia falciforme, dando uma frequência de 2,4 crianças afetadas para cada 1.000 nascimentos. No Brasil, a doenca falciforme é a doença hereditária monogênica mais comum, estimando-se que haja entre 20 a 30 mil pacientes portadores desta doenca. O transplante de células-tronco hematopoéticas alogênico de medula óssea (TCTH alo) é atualmente a única modalidade terapêutica capaz de curar pacientes com hemoglobinopatias. Neste artigo discutiremos os dados disponiveis na literatura e sugerimos os critérios para a indicação do TMO nas hemoglobinopatias. Rev. Bras. Hematol. Hemoter. 2010;32(Supl. 1):46-53.
\end{abstract}

Palavras-chave: Hemoglobinopatias; talassemia; doenças falciformes; transplante de medula óssea.

\section{Introdução}

Os distúrbios hereditários das hemoglobinas são as doenças genéticas mais frequentes do homem e mais difundidas no mundo, abrangendo, sobretudo continentes como África, Américas, Europa e extensas regiões da Ásia. Estimase que haja 270 milhões de portadores de hemoglobinopatias no mundo, dos quais 80 milhões são portadores de talassemia. Aproximadamente 60 mil crianças nascem anualmente no mundo com talassemia e 250 mil com anemia falciforme dando uma frequência de 2,4 crianças afetadas para cada mil nascimentos. ${ }^{1}$

\section{Doenças falciformes}

Anemia falciforme (AF) é a doença hereditária monogênica mais comum do Brasil, ocorrendo predominantemente entre afrodescendentes. No Brasil, distribui-se heterogeneamente, sendo mais frequente nos estados do Norte e Nordeste. Estima-se que cerca de 4\% da população geral brasi-

\footnotetext{
${ }^{1}$ Hematologia/ Hemoterapia/ Transplante de Medula Óssea - Faculdade de Medicina de Ribeirão Preto, Universidade de São Paulo Departamento de Clínica Médica - Ribeirão Preto-SP.

${ }_{3}^{2}$ Hematologial TMO. Médico Assistente do HCFMRP-USP - Ribeirão Preto-SP.

Hematologia / TMO. Médico Assistente do HCFMRP-USP - Ribeirão Preto-SP.

${ }^{4}$ Hematologial Hemoterapia. Diretora do Hemorio - Rio de Janeiro-RJ.

${ }_{5}^{5}$ Hematologia / Hemoterapia. Professor Associado da Faculdade de Ciências Médicas da Santa Casa - São Paulo-SP.

${ }^{6}$ Hematologia. Salvador-BA.

${ }^{7}$ Hematologial Hemoterapia. Médico Assistente da Fundação Hemocentro - Ribeirão Preto-SP.

${ }^{8}$ Hematologia/Imunologial TMO. Professor Titular FMRP-USP, coordenador da Unidade de TMO do HCFMRP-Ribeirão Preto-SP.
}

Faculdade de Medicina de Ribeirão Preto, Universidade de São Paulo - Ribeirão Preto-SP.

Correspondência: Belinda Pinto Simões

Rua Pedro Barbieri, 9003

14093-210 - Ribeirão Preto-SP - Brasil

E-mail:bpsimoes@fmrp.usp.br

Doi: 10.1590/S1516-84842010005000020 
leira e $6 \%$ a $10 \%$ dos afrodescendentes são portadores do traço falciforme (Hb AS). Dados do Programa Nacional de Triagem Neonatal (PNTN) mostram que, no estado da Bahia, a incidência da doença falciforme é de 1:650, enquanto a do traço falciforme é de 1:17, entre os nascidos vivos. No Rio de Janeiro, 1:1200 para a doença e 1:21 de traço. Em Minas Gerais, é na proporção de 1:1400 com a doença e de 1:23 com traço falciforme (Tabelas 1 e 2). Com base nesses dados, calcula-se que nasçam por ano, no País, cerca de 3.500 crianças com doença falciforme e 200 mil portadores de traço, número este que corresponde ao nascimento de uma criança doente para cada mil recém-nascidos vivos. Atualmente, estima-se que tenhamos 20 a 30 mil brasileiros portadores da doença falciforme (DF). Tal cenário permite tratar essa doença como problema de saúde pública no Brasil.

Tabela 1. Proporção de nascidos vivos diagnosticados com doença falciforme pelo Programa de Triagem Neonatal (PNTN)

\begin{tabular}{lc}
\hline \multicolumn{1}{c}{ Estados } & $\begin{array}{c}\text { Proporção/ } \\
\text { Nascidos Vivos }\end{array}$ \\
\hline Bahia & $1: 650$ \\
Rio de Janeiro & $1: 1.200$ \\
Pernambuco, Maranhão, Minas Gerais e Goiás & $1: 1.400$ \\
Espírito Santo & $1: 1.800$ \\
São Paulo & $1: 4.000$ \\
Mato Grosso do Sul & $1: 5.850$ \\
Rio Grande do Sul & $1: 11.000$ \\
Santa Catarina e Paraná & $1: 13.500$ \\
\hline
\end{tabular}

Tabela 2. Proporção de nascidos vivos diagnosticados com o traço falciforme pelo PNTN

\begin{tabular}{lc}
\hline \multicolumn{1}{c}{ Estados } & $\begin{array}{c}\text { Proporção/ } \\
\text { Nascidos Vivos }\end{array}$ \\
\hline Bahia & $1: 17$ \\
Rio de Janeiro & $1: 21$ \\
Pernambuco, Maranhão e Minas Gerais & $1: 23$ \\
Espírito Santo, Goiás & $1: 25$ \\
São Paulo & $1: 35$ \\
Paraná, Rio Grande do Sul e Santa Catarina & $1: 65$ \\
\hline
\end{tabular}

A pessoa pode ser homozigota (SS) ou heterozigota (AS) para a presença de hemoglobina S. As pessoas heterozigotas (AS) ou portadoras do traço falciforme são assintomáticas. $\mathrm{O}$ termo anemia falciforme (AF) é reservado para a forma de doença que ocorre nos homozigotos (SS). Além disso, o gene da hemoglobina S pode combinar-se com outras alterações hereditárias das hemoglobinas, como hemoglobina C, hemoglobina D e talassemia (alfa ou beta) gerando combinações que também são patológicas (hemoglobinopatia SC, S/beta-talassemia, etc.) denominadas doenças falciformes (DF).

A Portaria $\mathrm{N}^{\mathrm{o}} 1.391$, de 16 de agosto de 2005, institui no âmbito do Sistema Único de Saúde - SUS as diretrizes para a Política Nacional de Atenção Integral às Pessoas com doença falciforme e outras hemoglobinopatias, cujo objetivo é mudar a história natural desta doença no Brasil, reduzindo a morbimortalidade e trazendo qualidade de vida com longevidade a todas essas pessoas, tendo em vista que a doença falciforme encontra-se mais entre a população mais pobre e estima-se que até $25 \%$ das crianças não atingem os 5 anos de vida. A mortalidade perinatal também ainda é muito elevada em nosso país, variando de $20 \%$ a $50 \%$ (Figura 1 ).

Como pode ser visto nas Tabelas 1 e 2, o número de nascidos vivos com doença falciforme ou traço falciforme é extremamente elevado no País, constituído por uma população miscigenada, em que a proporção de afrodescendentes, inclusive, predomina em algumas regiões.

O total de óbitos por faixa etária de pessoas com doença falciforme no País durante o período de 2000 a 2005 pode ser visto no gráfico abaixo.

O quadro clínico da doença falciforme pode ser bastante variável. As manifestações clínicas mais comuns incluem anemia, crises dolorosas agudas, síndrome torácica aguda, sequestro esplênico, acidente vascular cerebral (clinicamente detectável ou silencioso), disfunção pulmonar e renal crônica, retardo de crescimento e desenvolvimento sexual, levando a uma expectativa de vida reduzida. As causas de óbito mais comuns entre adultos com doenças falciformes são falência de órgãos ( 18\%), especialmente insuficiência

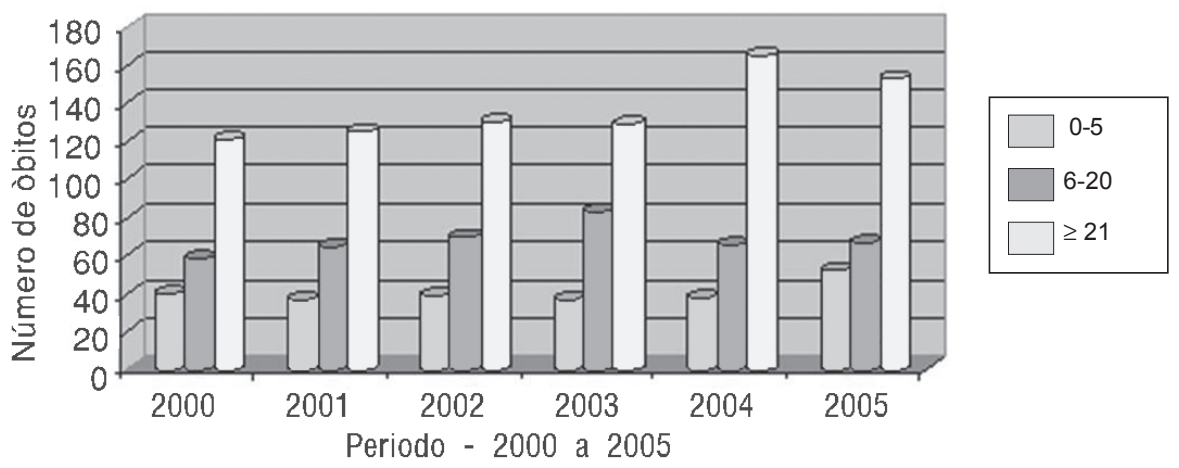

Figura I. Número de óbitos com doenças falciformes no Brasil entre os anos de 2000 a 2005 (dados do Ministério da Saúde, Comitê de Hemoglobinopatias) 
Tabela 3. Análise da eficácia e da toxicidade da hidroxiureia no tratamento da anemia falciforme baseada nos dados publicados até o momento (adaptado das referências 5 e 6)

\begin{tabular}{lll}
\hline Citação & Resultado & Grau de Evidência \\
\hline & Aumento Hb fetal & Alto \\
& Redução de crises dolorosas & Alto \\
Eficácia/efetividade & Redução de hospitalização & Alto \\
& Redução de eventos neurológicos & Insuficiente \\
& Redução de transfusão & Alto \\
& Mortalidade & Alto \\
& & \\
Toxicidade & Leucemia, SMD ou alterações citogenéticas & Baixo (suporta ausência de risco aumentado) \\
& Úlceras de perna & Alto (suporta ausência de risco aumentado) \\
& Neoplasias de pele & Insuficiente \\
& Neoplasias secundárias & Insuficiente \\
& Defeitos de espermatogênese & Baixo
\end{tabular}

renal, crise vaso-oclusiva aguda (33\%) e acidente vascular cerebral (AVC). ${ }^{2}$ A chance de ter um primeiro AVC aos $20,30 \mathrm{e}$ 45 anos é estimado em $11 \%, 15 \%$ e $25 \%$ respectivamente para pacientes com anemia falciforme (SS). Anormalidades em ressonância magnética são, porém, detectadas já em $22 \%$ de crianças com anemia falciforme. A presença de ataques isquêmicos transitórios (AIT) é mais comum do que se acreditava e pode propiciar AVC. ${ }^{3}$

A introdução da hidroxiureia no tratamento da anemia falciforme trouxe uma mudança significativa na evolução especialmente das crises vaso-oclusivas. ${ }^{4}$ Recente avaliação da eficácia da hidroxiureia no tratamento da anemia falciforme aponta para algumas situações que ainda requerem atenção especial, tendo em vista que a resposta ao tratamento com hidroxiureia é questionável. ${ }^{6,15}$ Algumas dúvidas em relação à eficácia e à toxicidade da hidroxiureia persistem, como evidenciado na tabela acima.

Assim, o benefício da hidroxiureia em termos de reduzir eventos neurológicos e de aumentar a sobrevida destes pacientes, apesar do número grande de pacientes já tratados, ainda é questionado. Para o controle e a prevenção de eventos neurológicos, o uso de transfusão crônica ainda parece ser o tratamento de escolha. Dois estudos avaliaram o impacto do regime de hipertransfusão no controle de eventos neurológicos, mostrando sua eficácia, mas demonstrando também que a interrupção da transfusão leva a recorrência do evento. ${ }^{7,8}$ Outra complicação frequente na anemia falciforme é o priapismo, que ocorre em aproximadamente $30 \%$ de homens com idade $<20$ anos, ocorrendo em metade dos pacientes com mais de 18 anos. ${ }^{9} \mathrm{O}$ priapismo tem pouca evidência na literatura de responder ao tratamento com hidroxiureia. Interessantemente, existe uma associação entre o priapismo recorrente e a hipertensão pulmonar no paciente com anemia falciforme. Está relacionado com níveis reduzidos de hemoglobina e com indicadores de hemólise (reticulócitos, bilirrubina, desidrogenase lática e aspartato aminotransferase). Pacientes com uma história de priapismo têm um risco cinco vezes superior de desenvolver hipertensão pulmonar. $^{10}$

\section{Talassemias}

As talassemias referem-se a um grupo heterogêneo de hemoglobinopatias caracterizados por uma redução da síntese de uma ou mais cadeias de globinas $(\alpha, \beta, \gamma, \delta \beta$, $\gamma \delta \beta, \delta$ ou $\varepsilon \gamma \delta \beta$ ). Trata-se da doença monogênica mais comum e especialmente nos países do mediterrâneo é problema maior de saúde pública. A ausência da cadeia beta da hemoglobina leva a eritropoese ineficaz, hiperplasia eritroide maciça na medula óssea e em sítios extramedulares e anemia hemolítica. Isto faz com que os pacientes necessitem de transfusões crônicas para sobreviver, levando inevitavelmente a uma sobrecarga de ferro importante. Mais do que a própria doença, é a sobrecarga de ferro que resulta em dano de múltiplos órgãos (coração, pâncreas, fígado, etc...). Os regimes de hipertransfusão e quelação adequada de ferro melhoraram a sobrevida de pacientes com talassemia transformando uma doença anteriormente fatal compatível com a vida. Apesar da melhora na sobrevida, a baixa aderência a terapia quelante ainda faz com que pacientes com talassemia maior tenham uma sobrevida diminuída em relação à população geral, sendo que poucos sobrevivem além dos 35 anos. ${ }^{1,11}$ As principais causas de óbito em pacientes com talassemia são secundárias à sobrecarga de ferro em coração e fígado.

Foi difícil localizar dados de prevalência de talassemia no Brasil. Segundo dados da Abrasta, existem hoje, no País, 485 pacientes com talassemia que necessitam de tratamento, dos quais 284 com talassemia major, $129 \mathrm{com} \mathrm{S} \beta$-talassemia e 72 com talassemia intermédia.

\section{Evidência na literatura do transplante de medula óssea em hemoglobinopatias}

Realizada busca na base de dados PubMed. Os termos buscados foram stem cell transplantation, bone marrow transplantation, sickle cell anemia. Os limites estipulados foram clinical trials, humans, meta-analysis e randomized controlled trials. 
Não foram encontrados estudos randomizados controlados nem para anemia falciforme nem para o TMO em talassemia. Quanto a estudos clínicos, foram encontrados 64 estudos publicados com transplante de medula óssea em talassemia e 36 publicações de transplante de medula óssea em anemia falciforme. Apesar da primeira descrição de cura de paciente com hemoglobinopatias com transplante de medula óssea já ter sido feita há mais de trinta anos, não há até o momento nenhum estudo randomizado controlado na literatura. No caso da anemia falciforme, isto pode dever-se ao quadro clínico por vezes muito complexo e às muitas comorbidades presentes nesta doença, o que torna a realização de estudos randomizados discutíveis do ponto de vista ético e faz com que tenhamos que tirar conclusões, pelo menos, de eficácia e toxicidade de estudos observacionais.

\section{Transplante de células-tronco hematopoéticas em doenças falciformes}

Atualmente, mais de 250 pacientes com doença falciforme foram transplantados em estudos clínicos na Europa e nos Estados Unidos da América (EUA). O objetivo primeiro destes estudos foi definir os riscos e os benefícios da terapêutica e caracterizar a história natural após TCTH. Nestes estudos, os critérios de elegibilidade foram inicialmente: idade entre 2-16 anos e a presença de AVE, ou STA, ou dor intensa recorrente. Porém, pacientes entre 1 e 27 anos já foram transplantados. A essência dos regimes mieloablativos de condicionamento se baseou no uso de bussulfano (BU) $14 \mathrm{mg}-16 \mathrm{mg} / \mathrm{kg}$ e da ciclofosfamida (CY) $200 \mathrm{mg} / \mathrm{kg}$, com ou sem globulina antitimócito (ATG) ou irradiação linfoide total (ILT). A maioria destes pacientes recebeu en- xertos de medula óssea (MO), e a ciclosporina e o metotrexato como profilaxia para a doença do enxerto contra o hospedeiro aguda (DECHa). Após uma mediana de cinco anos de seguimento, a sobrevida global e a sobrevida livre de doença foram de aproximadamente $90 \%-95 \%$ e 80\%-85\% respectivamente para pacientes com doador HLA compatível em todos os estudos. Entretanto, 5\% a 10\% destes pacientes morreram de complicações relacionadas ao transplante, sendo a DECH e o seu tratamento as principais causas de morte neste subgrupo. As frequências de DECHa e DECHc foram de $12 \%$ e $25 \%$ respectivamente. Reconstituição autóloga ocorreu em $5 \%$ a $10 \%$ dos pacientes. Nos dados franceses, a estimativa de rejeição aos três anos de TCTH foi de $27,8 \%$ sem o uso da globulina antitimocitária (ATG) e de somente $2,9 \%$ com o uso do ATG $(p=0,004)$. Dentre as complicações crônicas mais comuns, o déficit de crescimento e a esterilidade foram os mais bem avaliados. De uma forma geral, somente as crianças que receberam o TCTH próximo ou durante o estirão de crescimento é que cursaram com baixa estatura após o TCTH. Quanto à reversão das lesões preexistentes ao TCTH, as lesões em sistema nervoso central (SNC) e a função pulmonar estabilizaram ou melhoraram nos pacientes avaliados em todos os estudos. Quanto à pega da MO, quimerismo misto estável ocorreu em aproximadamente $25 \%$ das crianças com doença falciforme que receberam transplantes de doadores HLA idênticos na série multicêntrica americana. Neste contexto, os níveis de hemoglobina $\mathrm{S}(\mathrm{HbS})$ foram similares aos níveis dos doadores, mas nenhuma das crianças com quimerismo misto após o TCTH apresentou eventos dolorosos ou outras complicações relacionadas a doença falciforme, sugerindo que um enxertamento total das células do doador não é necessário para o sucesso do transplante.

Tabela 4. Transplante de células-tronco hematopoéticas alogênico mieloablativo para anemia falciforme

\begin{tabular}{|c|c|c|c|c|c|}
\hline & EUA & França & Bélgica & CIBMTR & Brasil \\
\hline Número & 59 & 87 & 50 & 67 & 8 casos \\
\hline Idade (mediana) & 9,9 & 9,5 & 7,5 & 10 & \\
\hline Condicionamento & $\begin{array}{l}\text { BuCy/ATG } \\
\text { BuCy/Campath }\end{array}$ & $\begin{array}{l}\text { BuCy } \\
\text { BuCy/ATG }\end{array}$ & $\begin{array}{l}\text { BuCy } \\
\text { BuCy/TLI } \\
\text { BuCy/ATG }\end{array}$ & BuCy & $\begin{array}{l}\text { BuCy/ATG } \\
\text { FluBu Mel } \\
\text { ATG }\end{array}$ \\
\hline Fonte CTH & $\mathrm{MO}$ & $\begin{array}{l}\text { MO } \\
\text { Cordão } \\
\text { Cordão MO } \\
\text { CTHP }\end{array}$ & $\begin{array}{l}\text { MO } \\
\text { Cordão }\end{array}$ & $\begin{array}{l}\text { MO } \\
\text { CTHP } \\
\text { Cordão }\end{array}$ & MO \\
\hline Quimerismo misto? & Sim & Sim & Sim & Sim & Sim \\
\hline Rejeição/ recidiva doença & $5(8,5 \%)$ & $7(8 \%)$ & $5(10 \%)$ & $9(13 \%)$ & $1 / 8$ casos \\
\hline $\mathrm{N}^{\circ} \mathrm{com} \mathrm{DECH}$ & $\begin{array}{l}\text { Aguda 25\% } \\
\text { Crônica } 12 \%\end{array}$ & $\begin{array}{l}\text { Aguda } 20 \% \\
\text { Crônica } 12,6 \%\end{array}$ & $\begin{array}{l}\text { Aguda } 40 \% \\
\text { Crônica 20\% }\end{array}$ & $\begin{array}{l}\text { Aguda 10\% } \\
\text { Crônica 22\% }\end{array}$ & $\begin{array}{l}\text { Aguda zero } \\
\text { Crônica zero }\end{array}$ \\
\hline$N^{0}$ de óbitos & $4(7 \%)$ & $6(7 \%)$ & $2(4 \%)$ & $3(4,5 \%)$ & zero \\
\hline Sobrevida livre de eventos & $50(85 \%)$ & $74(85 \%)$ & $43(86 \%)$ & $55(82 \%)$ & $100 \%$ \\
\hline Sobrevida Global & $93 \%$ & $93 \%$ & $96 \%$ & $95,5 \%$ & $100 \%$ \\
\hline
\end{tabular}


Uma abordagem interessante seria submeter pacientes jovens sem complicações ainda, ao TCTH, no sentido de prevenir as complicações futuras. Um único estudo avaliou o TCTH em pacientes portadores de anemia falciforme jovens sem complicações. Tratava-se de um grupo de 14 crianças africanas que moravam na Bélgica e que pretendiam voltar ao seu país de origem onde sabiam que não teriam um suporte terapêutico adequado e, desta maneira, quiseram submeter-se a um procedimento potencialmente curável. Nestas 14 crianças com menos de 14 anos não houve nenhum óbito e apenas em um caso houve recidiva da doença.

Como demonstrado na Tabela 4, apesar do número limitado de casos transplantados fica evidente o potencial desta abordagem terapêutica, sua eficácia e baixa toxicidade, tendo em vista que a sobrevida de pacientes com anemia falciforme é reduzida pelas complicações da própria doença.

\section{Indicações de transplante de células-tronco hematopoéticas em anemia falciforme}

A doença falciforme é fenotipicamente muito variável; desta maneira, a existência de potenciais fatores preditivos de evolução da doença poderia guiar as decisões terapêuticas. Entretanto, ainda há uma carência de fatores preditivos de evolução bem caracterizados para as crianças com SS ou talassemia $\mathrm{S} \beta 0$, e, na verdade, somente duas situações podem ser consideradas como fatores de risco para evolução grave: fluxo sanguíneo na artéria cerebral média persistentemente aumentado (fluxo $>200 \mathrm{~cm} / \mathrm{s}$ ) ao ultrassom Doppler (risco de $40 \%$ para a ocorrência de AVE) ${ }^{4}$; e a ocorrência precoce de STA. ${ }^{4}$ Pacientes com estas características podem ser considerados para intervenções precoces que possam minimizar (hidroxiureia, transfusão crônica) ou curar (transplante).

\section{A doença}

No único estudo que transplantou pacientes de forma "profilática", jovens sem complicações tiveram uma sobrevida global de 100\% com uma sobrevida livre de doença de $96 \%$. Estes dados sugerem que, se pudéssemos predizer um curso mais grave antes das complicações ocorrerem, poderíamos curar pacientes e evitar as complicações crônicas e debilitantes.

No momento, porém, fora de estudos clínicos, os critérios mais aceitos para se indicar um TCTH em pacientes com doenças falciformes são os recentemente publicados pela Escola Européia de Hematologia (ESH). Um dos seguintes itens a seguir:

- Crises vaso-oclusivas recorrentes e/ou priapismo (pelo menos dois episódios no ano precedente ou no ano anterior ao início de um programa de transfusão crônica) após uso de hidroxiureia por seis meses sem resposta ou contraindicação ao uso da mesma.
- Presença de vasculopatia cerebral demonstrada por ressonância nuclear magnética (RNM) e requerendo um programa de transfusão crônica.

- Presença de qualquer anormalidade à ressonância magnética angiográfica (RMA)/RNM (estenoses, oclusões).

- Doença pulmonar falciforme graus I e II

- Nefropatia falciforme (TFG entre $30 \%$ a $50 \%$ da esperada)

Outras indicações:

- Doppler transcraniano anormal

- Hipertensão pulmonar

- Infarto cerebral silencioso

- Recaída da anemia falciforme após um primeiro TCTH

- S beta talassemia dependente de transfusões.

A idade limite a ser considerada, na grande maioria dos trabalhos, usa o critério da talassemia como corte, ou seja 16 anos. Este critério, porém, não fica claro que seja tão crítico como parece ser em pacientes com talassemia maior submetidos a regime de transfusão crônica. Assim, fica a sugestão do consenso em não limitar a idade no TCTH para anemia falciforme.

Houve ainda as recomendações a seguir pelo grupo participando do Consenso:

- Rigorosa selecão dos pacientes, levando em consideração todos os fatores de risco: clínicos, laboratoriais, sociais e econômicos de cada indivíduo

- Definir protocolo nacional de tratamento (Único para todos os centros)

- Manter um Centro Registrador para reunião dos dados

- Rediscutir as indicações após dois anos de resultados (no próximo consenso).

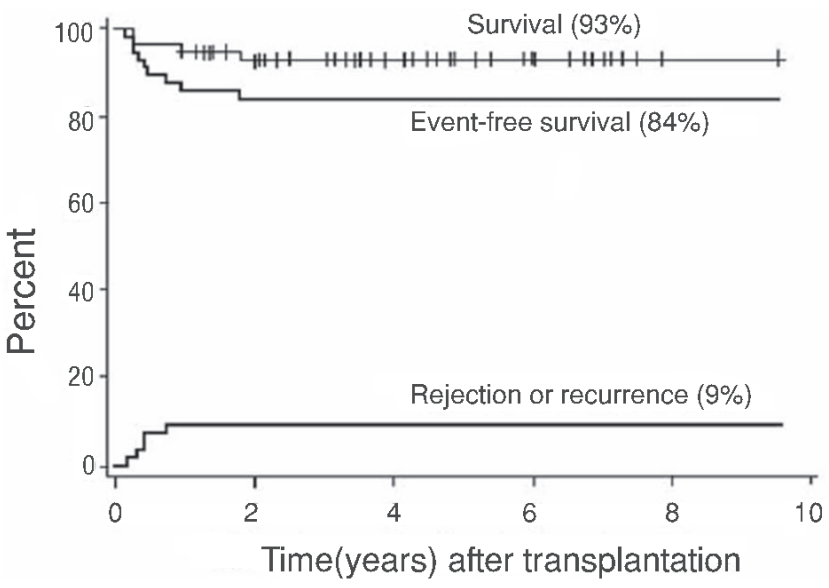

Figura 2. Resultados do TCTH alogênico em pacientes com anemia falciforme. Como eventos, foram considerados óbito, recidiva da doença e rejeição do enxerto. Mediana de seguimento 6 anos. Adaptado de referência 12 


\section{Transplante de células-tronco hematopoéticas em talassemia}

O primeiro caso transplantado para talassemia foi descrito no ano de 1982 pelo grupo de Seattle. Até o ano de 1999, a informação era de que estava vivo e bem. A maior experiência em TCTH em talassemia vem do grupo de Pesaro (Tabela 2). Logo ficou evidente que havia pacientes que se beneficiam mais do TCTH do que outros e assim foram subdivididos no que hoje conhecemos como as classes de Pesaro:

\footnotetext{
Fatores de Risco

Hepatomegalia

Fibrose portal em biópsia hepática pré-TCTH

Quelação de ferro pré-TCTH inadequada

Avaliação da Terapia Quelante de Ferro

Adequado se a terapia quelante de ferro foi iniciada até 18 meses depois da primeira transfusão e é utilizada em infusão subcutânea de 8 a 10 hs ao dia por 5 dias por semana

Inadequada caso não seja como descrito acima

Avaliação da categoria de risco

Classe I: sem fatores de risco

Classe II: 1 a 2 fatore de risco

Classe III: todos os três fatores de risco
}

- Idade $<16$ anos

- Pesaro classes 1 e 2

- Doadores HLA idênticos sendo a fonte de CTHP medula óssea, sangue periférico ou cordão umbilical.

\section{Conclusões}

O transplante de células-tronco hematopoéticas alogênico constitui-se na única opção curativa em pacientes com hemoglobinopatias. O uso desta modalidade terapêutica no tratamento da talassemia foi extensivamente empregado na Itália, tendo em vista a alta incidência da doença naquela região. Já quanto à anemia falciforme, os dados são mais restritos. Neste sentido, porém, vale uma reflexão a respeito dos motivos dos poucos casos transplantados com anemia falciforme na literatura, especialmente no momento em que pensamos as indicações de TCTH no Brasil.

Lauren Smith e colaboradores, em um artigo publicado no jornal Pediatrics, com o título "Sickle Cell Disease: A question of equity and quality" faz uma constatação surpreendente: apesar de a anemia falciforme ser quase três vezes mais prevalente do que a fibrose cística nos EUA, o gasto com os pacientes com fibrose cística (incluindo-se aqui verbas públicas e privadas para pesquisa e tratamento) são quase nove vezes maiores do que para os pacientes com anemia falciforme. Em um dos últimos parágrafos co-
Tabela 5. Resultados de transplante de células-tronco hematopoéticas alogênico em pacientes com talassemia maior

\begin{tabular}{|c|c|c|c|c|}
\hline & Pesaro 1 & Pesaro 2 & Pesaro $^{13}$ (total) & Inglaterra \\
\hline & 222 & 107 & 1030 & 55 \\
\hline Idade & $<16$ anos & 17 a 35 anos & 1 a 35 & 6,4 anos \\
\hline Condicionamento & $\begin{array}{l}\text { Bu } 14 \\
\text { Cy } 200\end{array}$ & $\begin{array}{l}\text { Bu14, Cy200 } \\
\text { Hydrea } \\
\text { Azatioprina } \\
\text { Fludara }\end{array}$ & Bu14 Cy200 & $\begin{array}{l}\text { Bu } 14 \\
\text { Cy } 200\end{array}$ \\
\hline Sobrevida Global & $\begin{array}{l}\mathrm{Cl}-93 \% \\
\mathrm{CIII}-80 \%\end{array}$ & $66 \%$ & $71 \%$ & $94,5 \%$ \\
\hline $\begin{array}{l}\text { Sobrevida livre } \\
\text { de eventos }\end{array}$ & $\begin{array}{l}\mathrm{Cl}-89 \% \\
\mathrm{CIII}-55 \%\end{array}$ & $62 \%$ & $68 \%$ & $81,8 \%$ \\
\hline $\begin{array}{l}\text { Mortalidade } \\
\text { rel tratamento }\end{array}$ & $12 \%$ & $27 \%$ a $37 \%$ & $12 \%$ a $37 \%$ & $5,4 \%$ \\
\hline Rejeição & $4 \%$ & $4 \%$ & $4 \%$ & $13 \%$ \\
\hline $\mathrm{DECHa}$ & & & $17 \%$ & $31 \%$ \\
\hline $\mathrm{DECHC}$ & & & $8 \%$ & $14,5 \%$ \\
\hline
\end{tabular}

menta: "Não há dúvida que a raça faz diferença nos Estados Unidos...." e mais adiante “... a questão da raça tem sido instrinsicamente ligada com a anemia falciforme desde sua descrição. Apesar de ser pouco confortável contemplar isto, precisamos considerar a possibilidade de que, consciente ou inconscientemente, o bias racial afete os recursos disponíveis não apenas para a pesquisa mas também para o cuidado médico destes pacientes". 19

Como descrito na parte introdutória do nosso texto, fica claro que, em um país em que nascem em torno de 3.500 crianças com doenças falciformes ao ano, a abordagem e o peso das diferentes estratégias terapêuticas tenha que ser considerado de forma diferencial. O uso crônico de hidroxiureia, apesar de ter beneficiado um número importante de pacientes, tem suas indicações, limitações e toxicidades crônicas. Sendo assim, o transplante de medula óssea deveria ser

Vários outros centros reproduziram os resultados de Pesaro como pode ser evidenciado na Tabela 5.

\section{Indicações de transplante de células-tronco hematopoéticas em talassemias}

Ficam asssim estabelecidos como critérios de indicação de TCTH em talassemias todos os pacientes com: encarado como outra opção terapêutica também com indicações, limitações e toxicidades próprias.

\section{A nova Portaria que regulamenta os transplantes no Brasil}

Foi com imensa decepção que recebemos a nova portaria que regulamenta os transplantes no Brasil. Ali encontra- 


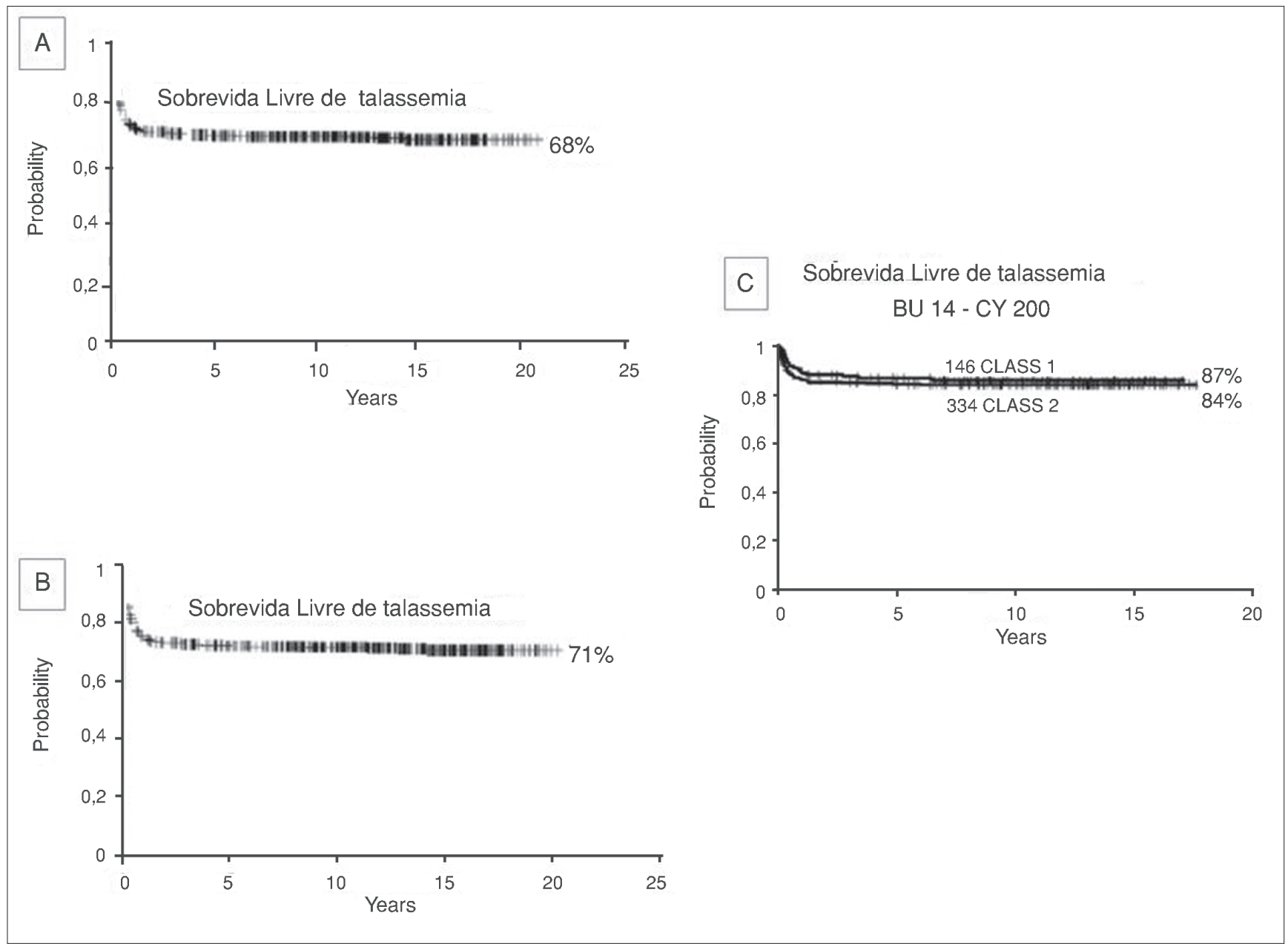

Figura 3. Transplante de células-tronco hematopoéticas em pacientes com talassemia maior transplantados no centro de Pesaro entre dezembro de 1981 a janeiro de 2003. A - Todos os casos, B - Pacientes transplantados com doadores HLA idênticos; C - Pacientes com classe I e II apenas

Tabela 6. Comparação entre os vários centros que publicaram resultados de TCTH alogênico para o tratamento de talassemia major (adaptado da ref. 15)

\begin{tabular}{lccc}
\hline \multicolumn{1}{c}{ Autor } & Pacientes & $\begin{array}{c}\text { Sobrevida } \\
\text { Global \% }\end{array}$ & $\begin{array}{c}\text { Sobrevida Livre de } \\
\text { Talassemia \% }\end{array}$ \\
\hline Di Bartolomeo & 111 & 90 & 86 \\
Argiolu & 37 & 88 & 88 \\
Clift & 68 & 94 & 81 \\
Lawson & 54 & 95 & 82 \\
Ghavamzadeh & 60 & 83 & 73 \\
Dennison & 50 & 76 & 68 \\
Lin & 28 & 86 & 82 \\
LI & 44 & 86 & 82 \\
Issaragrisli & 21 & 76 & 53 \\
Hongeng & 28 & 92 & 82 \\
\hline
\end{tabular}

se no anexo VII o seguinte texto: "As propostas de inclusão de novas indicações para TCTH oriundas das sociedades médicas, que não apresentarem nível de evidência que sustente sua recomendação inequívoca, deverão ser encaminhadas, técnico-cientificamente justificadas, à Coordenação-Geral do Sistema Nacional de Transplantes (SNT). Esta definirá, em conjunto com o Inca e a Câmara Técnica Nacional, para cada indicação aceita para avaliação, centros de excelência onde se desenvolverão estes transplantes, como projeto de pesquisa, devidamente submetido à Conep e coordenado pelo MS, para a devida decisão sobre inclusão em Regulamento Técnico, baseada na análise da efetividade e benefício do transplante."

A portaria, a nosso ver, persiste no erro de excluir a doenca hereditária mais frequente no Brasil e, desta maneira, impedir aos pacientes, que já apresentam uma qualidade de vida tão ruim, o acesso a um procedimento que poderia curá-los. 


\begin{abstract}
Hemoglobinopathies are the most prevalent genetic diseases in man. Most cases are described in Europe, Africa and in the Americas. About 270 million hemoglobinopathy carriers are alive today with 80 million being carriers of thalassemia. We estimate that, throughout the world, about 60,000 children are born annually with thalassemia and 250,000 with sickle cell disease with an estimated frequency of 2.4 children in every 1000 births. Sickle cell disease is the most common monogenic hereditary disease in Brazil with a total of from 20,000 to 30,000 patients. Allogeneic stem cell transplantation is the only curative approach. Here we describe published data and propose criteria to indicate stem cell transplantation in thalassemia and sickle cell disease patients. Rev. Bras. Hematol. Hemoter. 2010;32(Supl. 1):46-53.
\end{abstract}

Key words: Hemoglobinopathies; thalassemia; sickle cell disease; bone marrow transplantation.

\section{Referências Bibliográficas}

1. Modell B, Khan M, Darlison M, et al. A national register for surveillance of inherited disorders: beta thalassaemia in the United Kingdom. Bull World Health Organ. 2001;79:1006-13.

2. Platt OS, Brambilla DJ, Rosse WF, et al. Mortality in sickle cell disease. Life expectancy and risk factors for early death. N Engl J Med. 1994;330(23):1639-44.

3. White DA, Moinuddin A, McKinstry RC, et al. Cognitive screening for silent cerebral infarction in children with sickle cell disease. J Pediatr Hematol Oncol. 2006;28(3):166-9.

4. Steinberg MH, Barton F, Castro O, et al. Effect of hydroxyurea on mortality and morbidity in adult sickle cell anemia: risks and benefits up to 9 years of treatment. JAMA. 2003; 289 (13):1645-51.

5. Lanzkron S, Strouse JJ, Wilson R, et al. Systematic review: Hydroxyurea for the treatment of adults with sickle cell disease. Ann Intern Med. 2008;148(12):939-55.

6. Strouse JJ, Lanzkron S, Beach MC, et al. Hydroxyurea for sickle cell disease: a systematic review for efficacy and toxicity in children. Pediatrics. 2008;122(6):1332-42.

7. Adams RJ, Brambilla D. Discontinuing prophylactic transfusions used to prevent stroke in sickle cell disease. N Engl J Med. 2005; 353(26):2769-78.

8. Lezcano NE, Odo N, Kutlar A, Brambilla D, Adams RJ. Regular transfusion lowers plasma free hemoglobin in children with sicklecell disease at risk for stroke. Stroke. 2006;37(6):1424-6.

9. Nolan VG, Wyszynski DF, Farrer LA, Steinberg MH. Hemolysisassociated priapism in sickle cell disease. Blood. 2005;106 (9):3264-7.

10. Kato GJ, Gladwin MT, Steinberg MH. Deconstructing sickle cell disease: reappraisal of the role of hemolysis in the development of clinical subphenotypes. Blood Rev. 2007;21(1):37-47.

11. Modell B, Khan M, Darlison M. Survival in beta-thalassaemia major in the UK: data from the UK Thalassaemia Register. Lancet. 2000;355(9220):2051-2.

12. Michlitsch JG, Walters MC. Recent advances in bone marrow transplantation in hemoglobinopathies. Curr Mol Med. 2008;8(7): 675-89.

13. Storb RF, Lucarelli G, McSweeney PA, Childs RW. Hematopoietic cell transplantation for benign hematological disorders and solid tumors. Hematology Am Soc Hematol Educ Program. 2003;372-97.
14. Lawson SE, Roberts IA, Amrolia P, et al. Bone marrow transplantation for beta-thalassaemia major: the UK experience in two paediatric centres. Br J Haematol. 2003;120(2):289-95.

15. Lucarelli G, Gaziev J. Advances in the allogeneic transplantation for thalassemia. Blood Rev. 2008;22(2):53-63.

16. La Nasa G, Argiolu F, Giardini C, et al. Unrelated bone marrow transplantation for beta-thalassemia patients: The experience of the Italian Bone Marrow Transplant Group. Ann N Y Acad Sci. 2005;1054:186-95

17. La Nasa G, Caocci G, Argiolu F, et al. Unrelated donor stem cell transplantation in adult patients with thalassemia. Bone Marrow Transplant. 2005;36(11):971-5.

18. Jaing TH, Yang CP, Hung IJ, et al. Transplantation of unrelated donor umbilical cord blood utilizing double-unit grafts for five teenagers with transfusion-dependent thalassemia. Bone Marrow Transplant. 2007;40(4):307-11.

19. Smith LA, Oyeku SO, Homer C, Zuckerman B. Sickle cell disease: a question of equity and quality. Pediatrics. 2006; 117(5): 1763-70.

Este artigo foi avaliado pelos coordenadores das Diretrizes do Transplante de Medula Óssea da Sociedade Brasileira de Transplante de Medula Óssea, Luis Fernando Bouzas, Prof. Julio Cesar Voltarelli e Nelson Hamerschlak, e publicado após avaliação e revisão do editor, Milton Artur Ruiz.

Conflito de interesse: sem conflito de interesse

Recebido: 06/11/2009

Aceito: $23 / 11 / 2009$ 